\title{
GAS CHROMATOGRAPHY-MASS SPECTROSCOPY STUDIES ON ETHANOLIC EXTRACT OF DRIED LEAVES OF CATHARANTHUS ROSEUS
}

\author{
GAURAV M DOSHI ${ }^{1 *}$, BERNADETTE D MATTHEWS ${ }^{2}$, PRATIP K CHASKAR ${ }^{3}$ \\ ${ }^{1}$ Department of Pharmacology, ${ }^{2}$ Department of Quaity Assurance, ${ }^{3}$ Department of Pharmaceutical Chemistry, Vivekanand Education \\ Society's College of Pharmacy, Mumbai, India. Email: gaurav.pharmacology@gmail.com
}

Received: 17 November 2017, Revised and Accepted: 20 March 2018

\section{ABSTRACT}

Objective: Phytochemical screening of the ethanolic extract of Catharanthus roseus disclosed the presence of alkaloids, terpenoids, phenols, tannins, saponins, quinines, flavonoids, and proteins. In the present research work, we have identified and confirmed the structures of the constituents present by means of a hyphenated technique of gas chromatography-mass spectrometry (GC-MS) from the extract.

Method: Shade-dried leaves of $C$. roseus were powdered and extracted by means of Soxhlet extraction using ethanol as a solvent. Crude extract obtained was utilized for GC-MS.

Results: A total of 15 components were identified, some of which were $n$-hexadecanoic acid, ethyl ester, Vitamin E, 9,12,15-octadecatrienoic acid,2[(trimethylsilyl)oxy]-1-[\{(trimethylsilyl)oxy\}methyl] ethyl ester, phytol, 3-epivindolinine, and oleic acid.

Conclusion: GC-MS studies helped us to assess the phytochemical constituents based on retention time, molecular formula, molecular weight and the corroboration of MS libraries. In future, C. roseus leaves may be subjected to diverse types of extraction methodologies, and a number of various elucidated phytoconstituents can be studied for their ethnopharmacological significance and applicability citing literature.

Keywords: Catharanthus roseus, Gas chromatography, Mass spectroscopy, Phytol, 3-Epivindolinine, Oleic acid.

(c) 2018 The Authors. Published by Innovare Academic Sciences Pvt Ltd. This is an open access article under the CC BY license (http://creativecommons. org/licenses/by/4. 0/) DOI: http://dx.doi.org/10.22159/ajpcr.2018.v11i6.23704

\section{INTRODUCTION}

Discovery of natural plant-derived drugs from natural botanical herbarium has been the major breakthrough in paving the way for natural product chemistry [1]. Natural products are a substantial source of new drugs. They may have various sources or origins such as terrestrial plants, microorganisms, marine organisms, and terrestrial vertebrates, and invertebrates [2,3]. From time immemorial, they play a significant role as phytochemicals in treating and preventing a number of human diseases. Phytochemicals have been derived from the Greek word "phyto" meaning plant. Phytochemicals are biologically active, naturally occurring, non-nutritive chemical compounds found in plants having a protective and disease preventive activity. Plants produce such chemicals to safeguard themselves, but research reveals that they also have the ability to protect humans against diseases [4]. The subject of phytochemistry has been developed in recent years as a strict discipline, closely related to both natural product organic chemistry and plant biochemistry [1].

Plant metabolism has been able to separate phytochemicals in two categories, namely, primary or secondary. Primary constituents include the common sugars, amino acids, proteins, purines and pyrimidines of nucleic acids, and chlorophylls. Secondary constituents are the remaining plant chemicals such as alkaloids, terpenes, flavonoids, lignans, plant steroids, curcumines, saponins, phenolics, flavonoids, and glucosides [4]. In a pharmaceutical landscape, plants with a long history of use in ethnomedicine are considered as a rich source of active phytoconstituents that provide medicinal or health benefits against various ailments and diseases. One such family with extensive traditional use is Apocynaceae family.

Catharanthus roseus is one of the most important medicinal plants belonging to this family. C. roseus or Periwinkle (Nayantara or Sadabahar) is an erect bushy perennial herb and evergreen shrub. It grows wildly in the Indian subcontinent in southern Asia and with medicinal importance in Australia, Africa, and Southern Europe. The leaves are long and they are arranged in the opposite pairs. They have oval to oblong shape, broad glossy green hairless with a pale midrib and a short petiole [5]. It has been reported to contain more than 400 types of different alkaloids. Some of the important are vinblastine, vincristine, vindesine, vindeline, tabersonine, ajmalicine, vinceine, vineamine, raubasin, reserpine, catharanthine, etc. [6]. Leaves are used in the treatment of menorrhagia, rheumatism, dyspepsia, indigestion, dysmenorrhea, diabetes, hypertension, menstrual disorders, antiallergic, anti-inflammatory, antimicrobial, antithrombotic, cardioprotective, antihelminthic, hypolipidemic, skin diseases, bleeding diarrhea, and antiviral properties. Currently, herbal research has been mainly focusing on isolation, characterization, identification, and quantification of bioactive constituents and secondary metabolites [7-13]. Gas chromatography-mass spectrometry (GC-MS) is one such sophisticated analytical technique used in identification, detection, and analysis of the constituents. It comprises GC coupled to a MS, by which complex mixtures of plantrelated compounds may be separated, identified, and quantified [14]. In the present work, we have identified and confirmed the structures of the active constituents by GC-MS from the ethanolic extract of dried leaves of $C$. roseus.

\section{MATERIALS AND METHOD}

\section{Collection and authentication}

- The fresh leaves of C. roseus were collected from Mumbai, Maharashtra, and air-dried at room temperature.

- The dried leaves' sample was authenticated by Agharkar Research Institute, Pune.

- The sample was stored in an airtight container at $6^{\circ} \mathrm{C}$.

\section{Extraction}

- The leaves of $C$. roseus were dried in the shade, powdered with a mechanical grinder, and passed through sieve no. 40. 


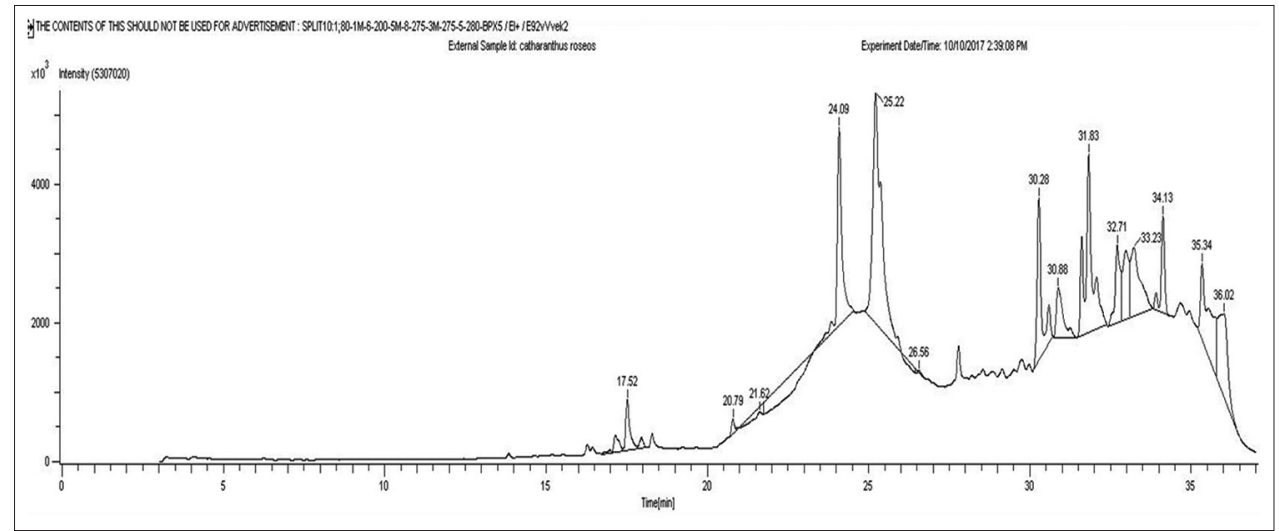

Fig. 1: Gas chromatography spectrum of Catharanthus roseus ethanolic extract

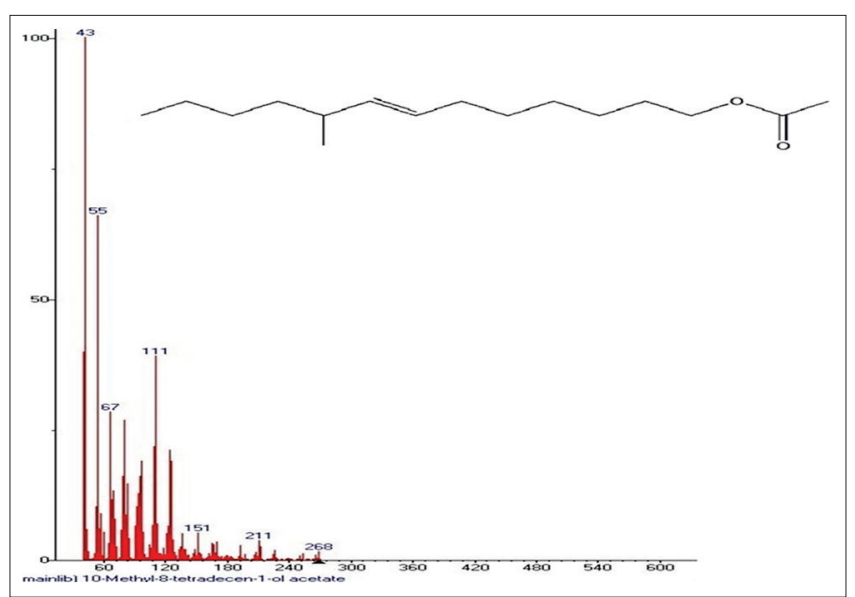

Fig. 2: Mass spectrum showing the presence of 10-methyl-8tetradecen-1-ol acetate

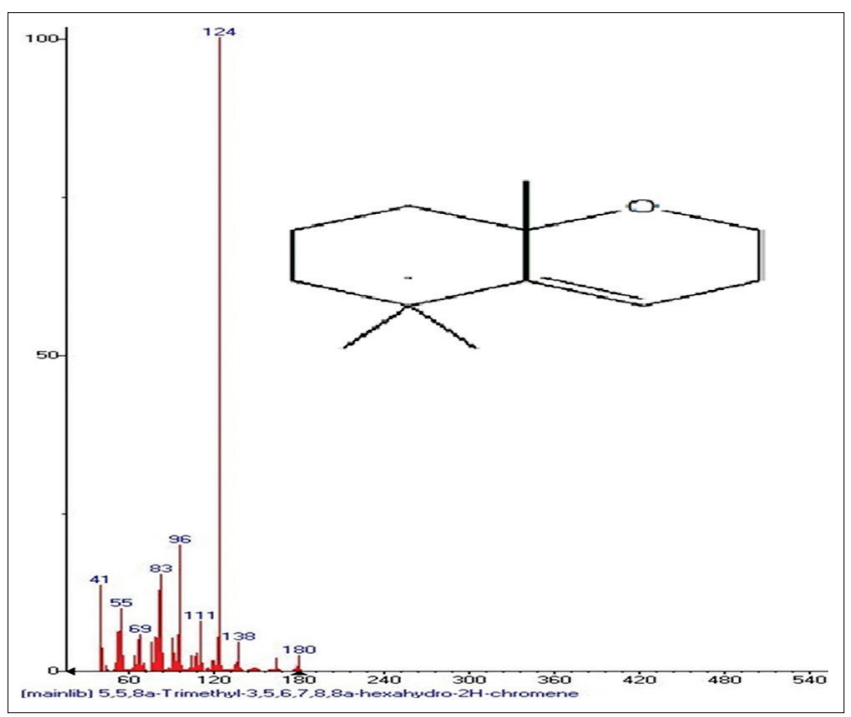

Fig. 3: Mass spectrum showing the presence of 5,5,8a-trimethyl$3,5,6,7,8,8 \mathrm{a}-h$ hexahydro-2H-chromene

- The dried powdered material (25 g) was extracted with $80 \%$ ethanol using Soxhlet apparatus at a temperature of $50^{\circ} \mathrm{C}$ for $21 \mathrm{~h}$.

- The solvent was then evaporated on a water bath at temperature maintained at $70^{\circ} \mathrm{C}$

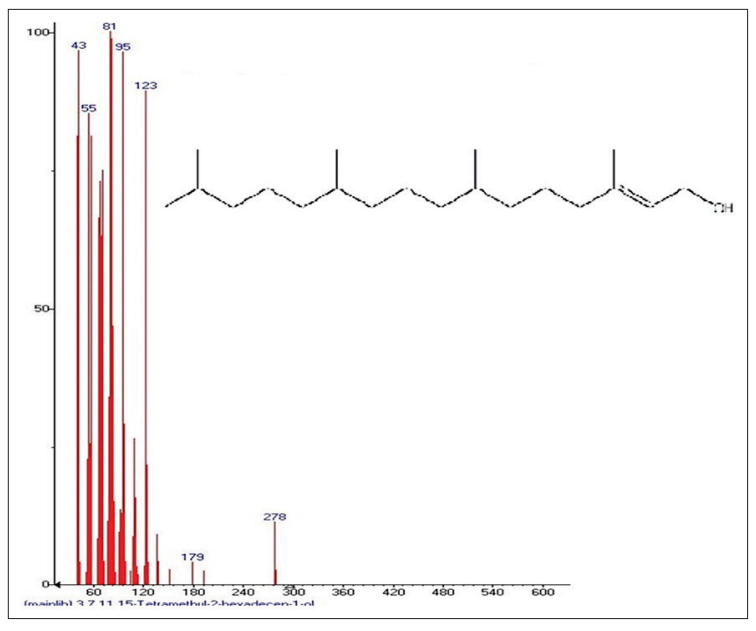

Fig. 4: Mass spectrum showing the presence of 3,7,11,15-Tetramethyl-2-hexadecen-1-ol

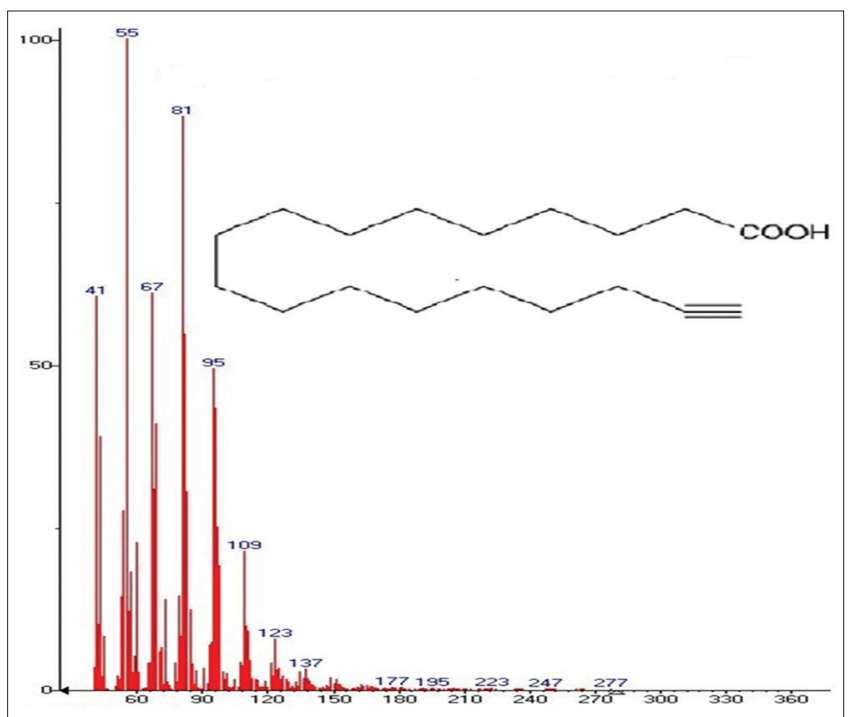

Fig. 5: Mass spectrum showing the presence of 17-octadecynoic acid

GC-MS

- The instrument used in the experimentation purpose was Joel, USA, with model of Accu Time-of-Flight GCV. The column details comprise capillary (type), semi-standard non-polar (class), and 30m/60m (length) 


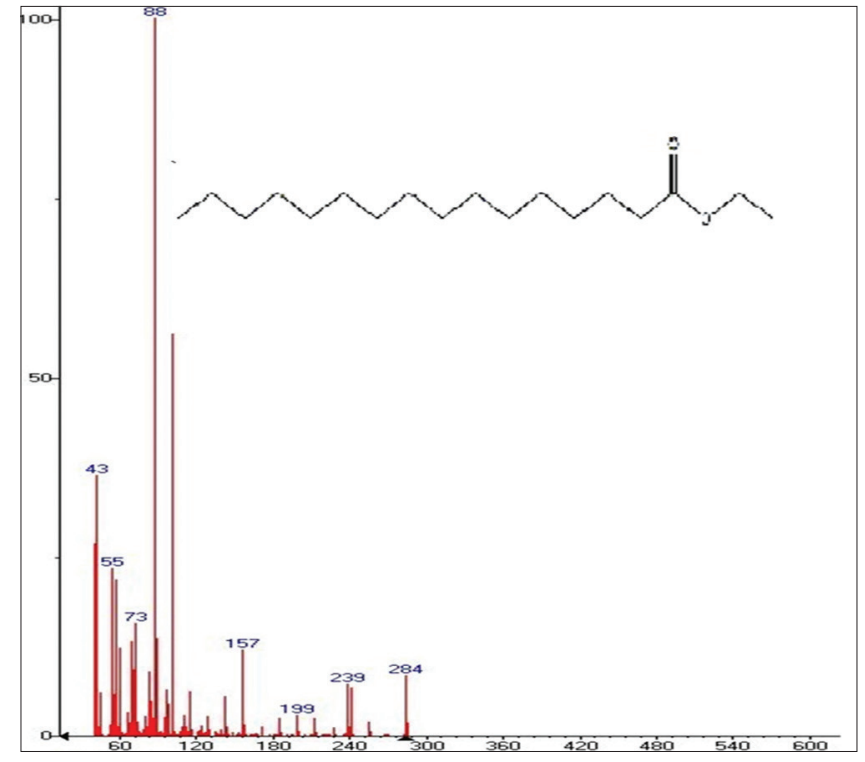

Fig. 6: Mass spectrum showing the presence of hexadecanoic acid, ethyl ester

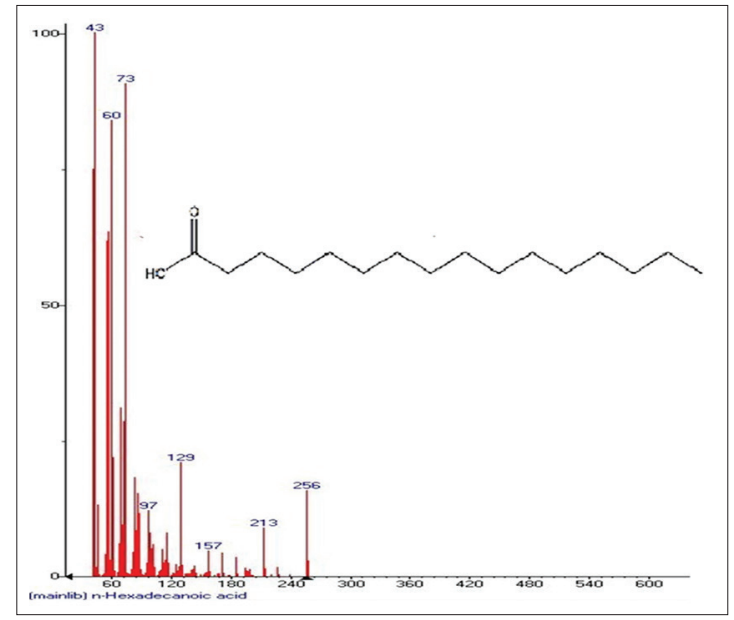

Fig. 7: Mass spectrum showing the presence of $\boldsymbol{n}$-hexadecanoic acid

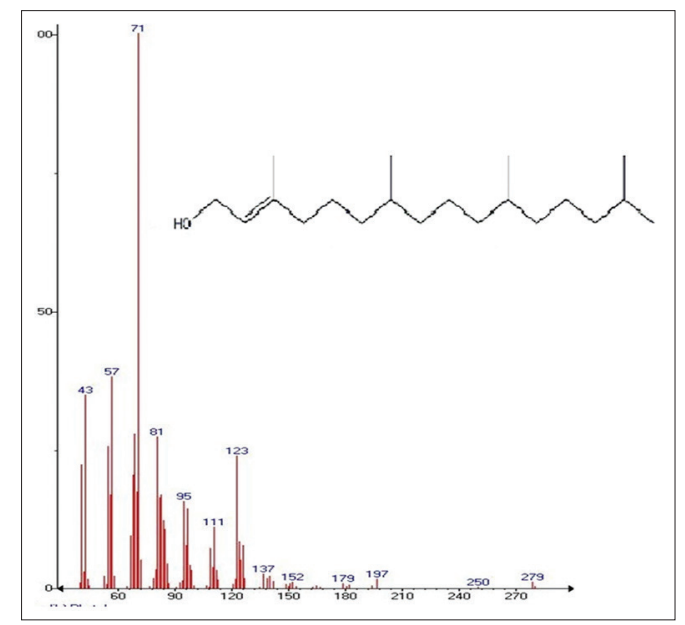

Fig. 8: Mass spectrum showing the presence of phytol

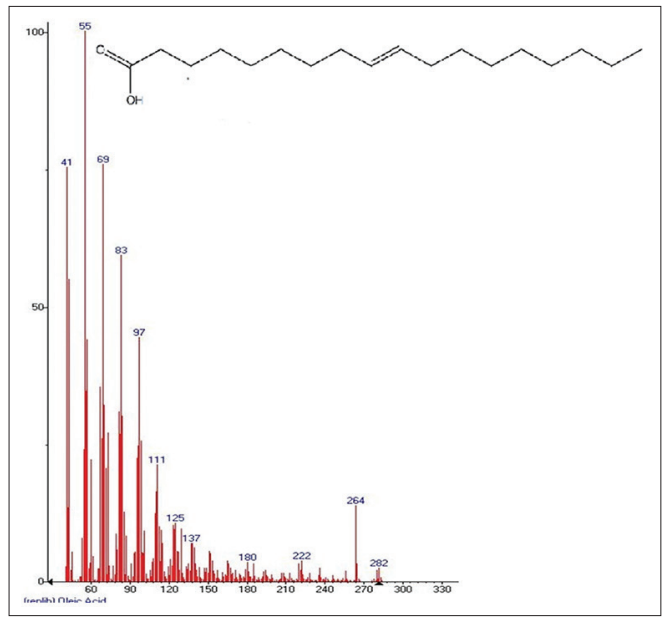

Fig. 9: Mass spectrum showing the presence of oleic acid

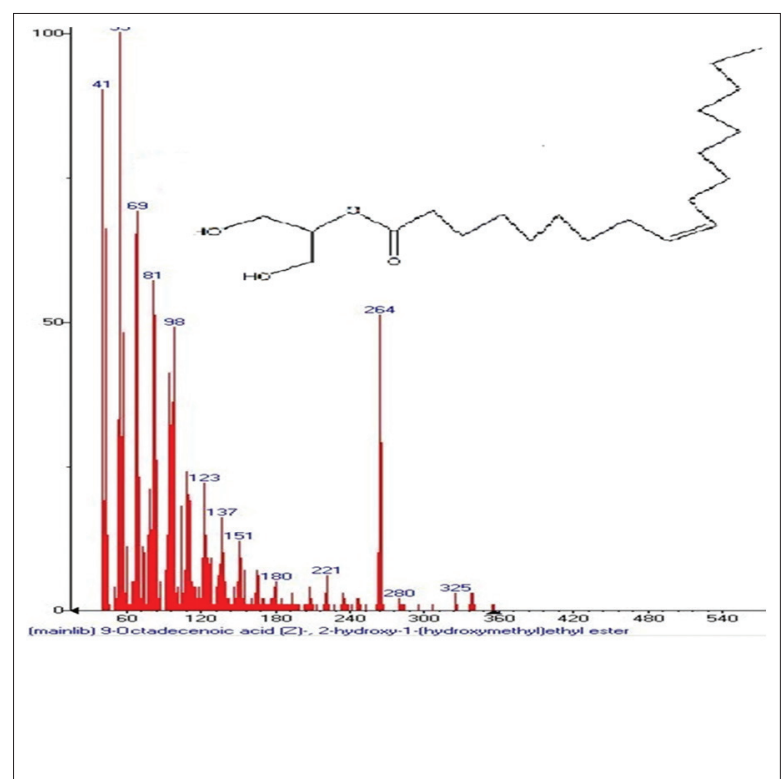

Fig. 10: Mass spectrum showing the presence of 9-octadecenoic acid(Z),2-hydroxy-1-(hydroxymethyl)ethyl ester

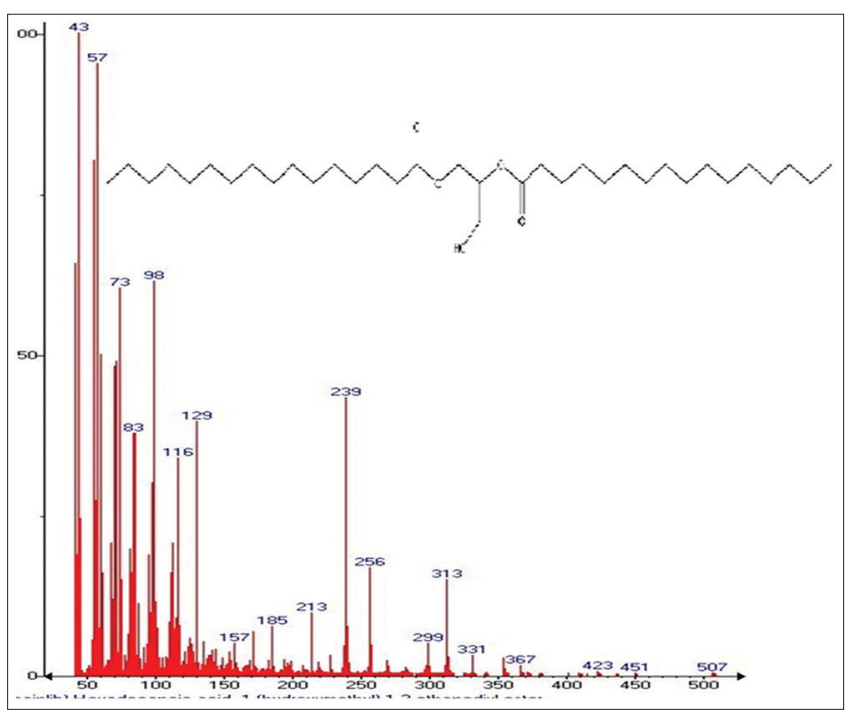

Fig. 11: Mass spectrum showing the presence of hexadecanoic acid-1-(hydroxymethyl)-1,2-ethanediyl ester 


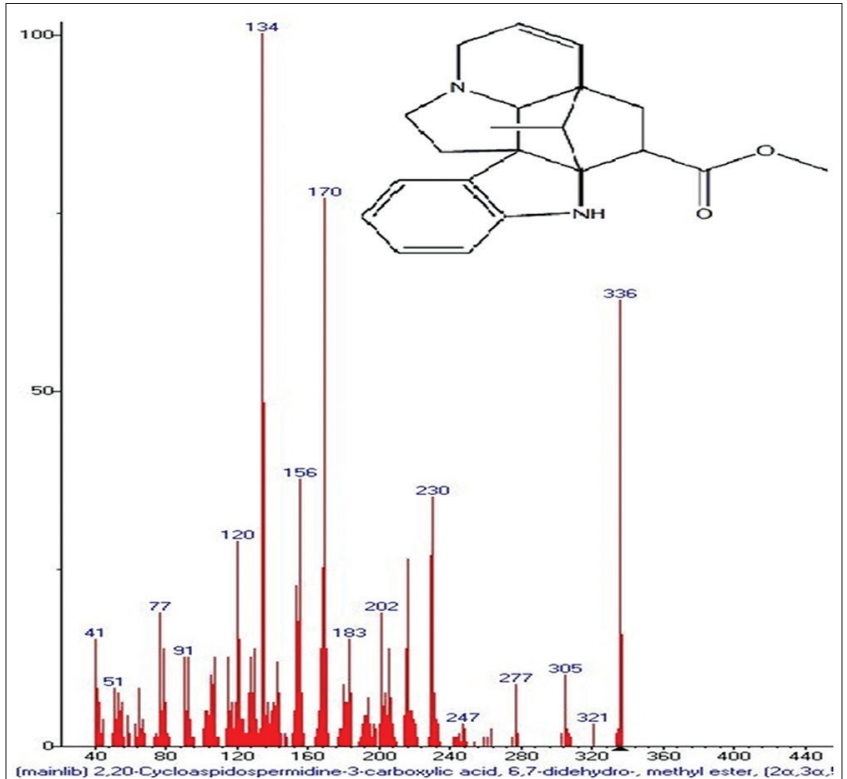

Fig. 12: Mass spectrum showing presence of 2,20-cycloaspidospermid-3-carboxylic acid,6,7-didehydro-methyl $\operatorname{ester}(2 \alpha, 3 \alpha, 5 \alpha, 12 \beta, 19 \alpha, 20 R)$

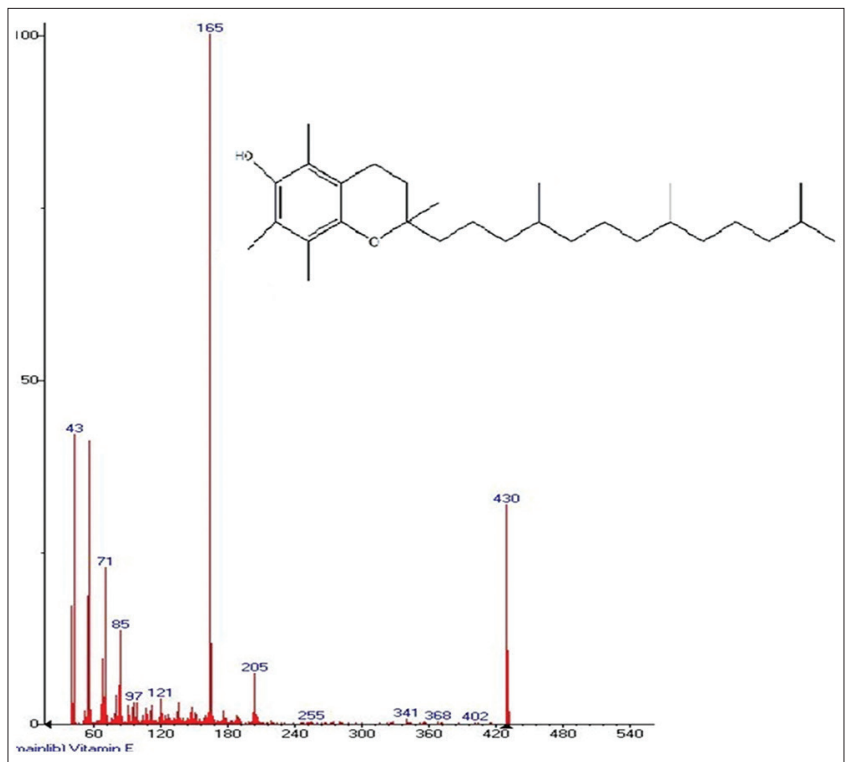

Fig. 13: Mass spectrum showing the presence of Vitamin E

with diameter of $0.25 \mathrm{~mm}$. The mobile phase used was chloroform. The carrier used was helium with heat rate of $2 \mathrm{k} / \mathrm{min}$ to $3 \mathrm{k} / \mathrm{min}$.

- The libraries used were NIST $2.0 \mathrm{f}$ and Fine, NIH, EINECS, TSCA, RTECS, HODOC, IRDB, and LIB for identification and interpretation of compounds.

\section{RESULTS AND DISCUSSION}

In the present GC-MS study, The term is 17-Octadecynoic acid. hexadecenol derivatives, palmitic acid, phytol, oleic acid, Isovindolinine, and tocopherols were eluted. The principal compounds found to be present in the extract were predominantly saturated and unsaturated fatty acids and their esters, diterpenes and methylated phenols, all of which possess a significant pharmacological activity. In the present research study, 15 compounds were identified by GCMS technique from C. roseus ethanolic extract (Fig. 1). 10-Methyl-8tetradecen-1-ol acetate (Fig. 2) with $m / z 268$ and fragment ions 43, 55,

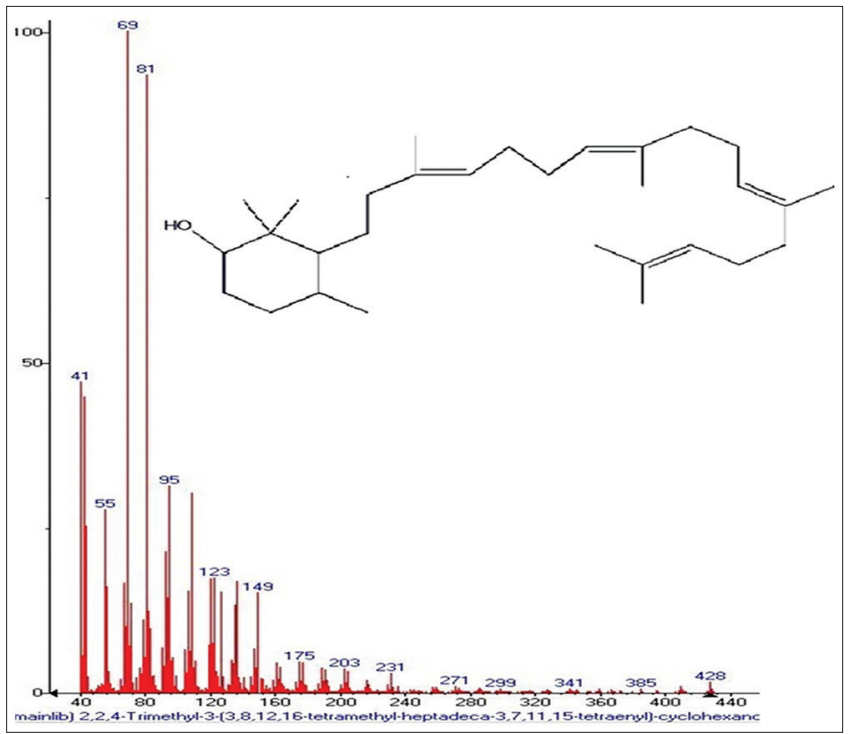

Fig. 14: Mass spectrum showing presence of 2,2,4-trimethyl3-(3,8,12,16-tetramethyl-heptadeca-3,7,11,15-tetraenyl)cyclohexanol

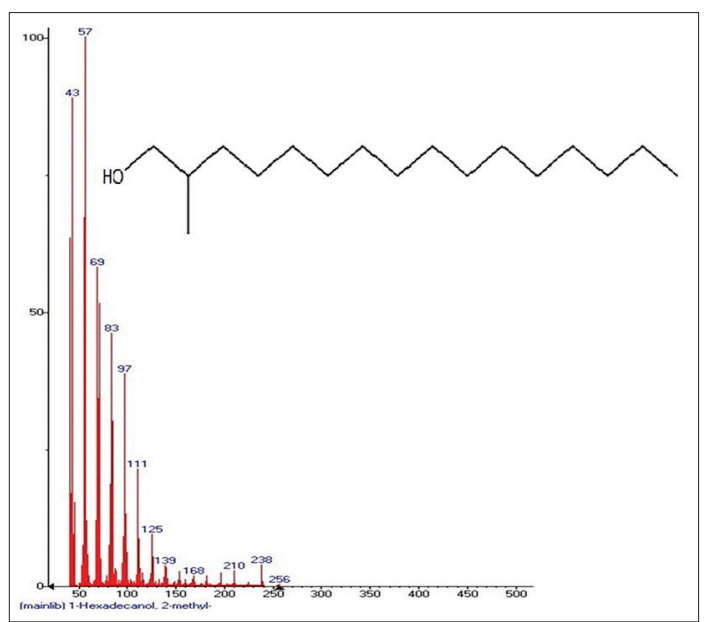

Fig. 15: Mass spectrum showing the presence of 2-methyl-1hexadecanol

67, 111, 151, 211, 268 and 5,5,8a-trimethyl-3,5,6,7,8,8a-hexahydro$2 H$-chromene (Fig. 3 ) with $m / z 180$ and fragment ions $41,55,69,83$, $96,111,124,138,180$ and 3,7,11,15-tetramethyl-2-hexadecen-1-ol (Fig. 4) with $m / z 296$ and fragment ions 43, 55, 81,95, 123, 179, 278 and 17-octadecynoic acid (Fig. 5) with $m / z 280$ and fragment ions 41, $55,67,81,95,109,123,137,177,195,223,247,277$ and hexadecanoic acid, ethyl ester (Fig. 6) with $m / z 284$ and fragment ions 43, 55, 73, 88, 157, 199, 239, 284 and n-hexadecanoic acid (Fig. 7) with $m / z 256$ and fragment ions 43, 60, 73, 97, 129, 157, 213, 256 are characterized. Phytol (Fig. 8) with $m / z 296$ and fragment ions 43, 57, 71, 81, 95, 111, 123, 137, 152, 179,197, 250, 279 and oleic acid (Fig. 9) with $\mathrm{m} / \mathrm{z}$ 282 and fragment ions $41,55,69,83,97,111,125,137,180,222$, 264, 282 and 9-octadecenoic acid(Z),2-hydroxy-1-(hydroxymethyl) ethyl ester (Fig. 10) with $\mathrm{m} / \mathrm{z} 356$ and fragment ions 41, 55, 69, 81, $98,123,137,151,180,221,264,280,325$ and hexadecanoic acid-1(hydroxymethyl)-1,2-ethanediyl ester (Fig. 11) with $\mathrm{m} / \mathrm{z} 568$ and fragment ions $43,57,73,83,98,116,129,157,185,213,239,256,299$, $313,331,367,423,451,507$ and the term is 2,20 -cycloaspidospermid3 -carboxylic acid-6,7-didehydro methyl ester- $(2 \alpha, 3 \alpha, 5 \alpha, 12 \beta, 19 \alpha$, 20R). (Fig. 12) with $m / z 336$ and fragment ions $41,51,77,91,120$, 134, 156, 170, 183, 202, 230, 247, 277, 305, 321, 336 and Vitamin E 


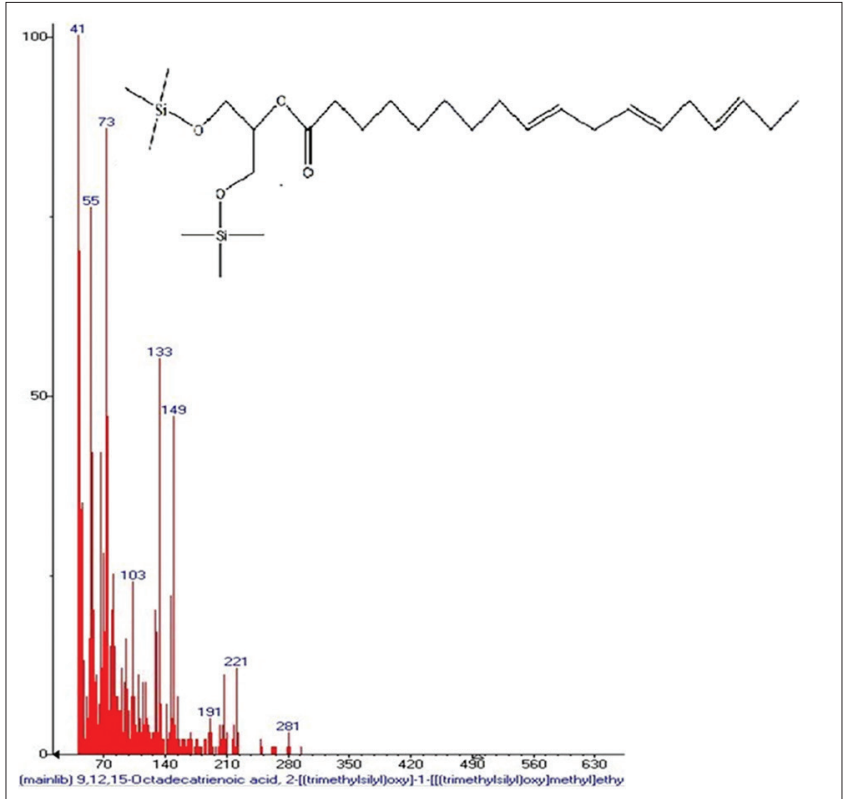

Fig. 16: Mass spectrum showing the presence of 9,12,15-octadecatrienoic acid,2-[(trimethylsilyl) oxy]-1-[\{( trimethylsilyl)oxy\}methyl]ethyl ester, (Z,Z,Z)

(Fig. 13) with $m / z 430$ and fragment ions $43,71,85,97,121,165,205$, 255, 341, 368, 402, 430 and 2,2,4-trimethyl-3-(3,8,12,16-tetramethylheptadeca-3,7,11,15-tetraenyl)-cyclohexanol (Fig. 14) with $m / z 428$ and fragment ions $41,55,69,81,95,123,149,175,203,231,271$, 299, 341, 385, 428 and 2-methyl-1-hexadecanol (Fig. 15) with $\mathrm{m} / \mathrm{z}$ 256 and fragment ions $43,57,69,83,97,111,125,139,168,210$, 238, 256 and 9,12,15-octadecatrienoic acid,2-[(trimethylsilyl)oxy]-1[\{(trimethylsilyl)oxy\}methyl]ethyl ester, (Z,Z,Z) (Fig. 16) with $\mathrm{m} / \mathrm{z} 496$ and fragment ions $41,55,73,103,133,149,191,221,281$, respectively, are seen prominently.

\section{CONCLUSION}

This research article will edify a researcher and the reader toward 15 compounds that have been screened from the ethanolic extract of C. roseus by a hyphenated technique of GC-MS. It will also help to build upon future research endeavors in related fields by further elaboration focusing on different extraction procedures and elucidation and comparison of various phytoconstituents and their ethnopharmacological activities by application of various chromatographic hyphenated techniques.

\section{ACKNOWLDGMENT}

We would like to express our gratitude to our college management for making available to us all the facilities required to complete our work. We would also like to acknowledge the help and guidance received from the SAIF Department, GC-MS Laboratory, Indian Institute of Management, Mumbai, with regard to the analytical segment.

\section{REFERENCES}

1. Harborne JB. Phytochemical Methods. $3^{\text {rd }}$ ed. New Delhi: Springer Publication House; 2005. p. 1-36.

2. Chin YW, Balunas MJ, Chai HB, Kinghorn AD. Drug discovery from natural sources. AAPS J 2006;8:E239-53.

3. Butler MS. The role of natural product chemistry in drug discovery. J Nat Prod 2004;67:2141-53.

4. Saxena M, Saxena J, Nema R, Singh D, Gupta A. Phytochemistry of medicinal plants. J Pharm Phytochem 2013;1:168-82.

5. Kabesh K, Senthilkumar P, Ragunathan R, Kumar RR. Phytochemical analysis of Catharanthus roseus plant extract and its antimicrobial activity. Int J Pure Appl Biosci 2015;3:162-72.

6. Hossain S, Hossain M, Haque Z, Moyen Uddin PK. Phytochemical Screening of Catharanthus Roseus and Ficus Racemosa Leaves Extracts: A statistical inference. Int J Bioassays 2015;4:3606-10.

7. Aja PM, Okorie UC, Ozougwu VE, Onya-Mmag EA, Agu KA, Nweke OL. Phytochemical and gas chromatography-mass spectrometric (GC-MS) analyses of Whitfieldia lateritia Leaf. Afr J Basic Appl Sci 2016;8:41-54

8. Das S, Sharangi AB. Madagascar periwinkle (Catharanthus roseus L.): Diverse medicinal and therapeutic benefits to humankind. J Pharm Phytochem 2017;6:1695-701.

9. Lwashina T. The structure and distribution of the flavonoids in plants. J Plant Res 2000;113:287-99.

10. Liu J, Liu Y, Pan Y, Zu YG, Tang ZH. Determination of alkaloids in Catharanthus roseus and Vinca minor by high-performance liquid chromatography-tandem mass spectrometry. Anal Lett 2016;49:1143-53.

11. Gopal KR, Bharathi VD, Sreemathi M, Krishnamoorthy C. Effect of different methods of drying on quality parameters in periwinkle (Catharanthus Roseus L.). Int J Sci Nat 2016;7:594-7.

12. Rency RC, Vasantha K, Maruthasalam A. Identification of bioactive compounds from ethanolic leaf extracts of Premna serratifolia L. using GC-MS. Biosci Disc 2015;6:96-101

13. Karuppasamy R, Veerabahu RM. GC-MS analysis of bioactive components of Myxopyrum serratulum A.W. Hill (Oleaceae). Int J Pharm Sci Rev Res 2016;38:30-5.

14. Chaskar PK, Tank SH, Doshi GM. Gas chromatography-mass spectroscopy studies on Cestrum nocturnum macerated methanolic extract. Asian J Pharm Clin Res 2017;10:259-63. 